\title{
CHRONIC ANTHROPOGENIC NOISE EXPOSURE AND SONGBIRD HEARING
}

\section{J. R. BARBER $\downarrow$ DEPARTMENT OF FISH, WILDLIFE AND CONSERVATION BIOLOGY COLORADO STATE UNIVERSITY FORT COLLINS}

\section{$\downarrow \quad$ INTRODUCTION}

As human populations have increased, our impact can now be felt even in the deepest remnants of wilderness (Vitousek et al. 1997). The resource demands of the ever-increasing human enterprise are creating substantial amplification of man-made pollution, including noise production. The dominant sources of anthropogenic noise are transportation networks, development (including energy, urban and industrial) and recreational activities. These activities are increasing faster than population growth. Between 1970 and 2007 the US population increased by approximately one third whereas (http://www.census.gov/compendia/statab/) traffic on US roads nearly tripled, to almost 5 trillion vehicle kilometers per year, (http://www.fhwa.dot.gov /ohim.tutw/tvpage.cfm.). Similar trends in shipping noise have also been observed in marine ecosystems, as discussed in reviews of noise impacts on marine animals (e.g., Nowacek et al. 2007).

Acoustical monitoring by the Natural Sounds Program of the U.S. National Park Service has documented increased ambient sound levels at hundreds of sites in a wide range of parks and habitats. Remote backcountry areas are not immune, because air transportation noise is widespread, and high traffic corridors generate substantial noise increases on the ground. For example, anthropogenic sound is audible at the Snow Flats backcountry site in Yosemite National Park nearly $70 \%$ of the time during peak traffic hours (Figures 1 and 2). Aircraft noise increases the median sound level by more than $3 \mathrm{~dB}(\mathrm{~A}) 1$ during the hours between 8 am and $9 \mathrm{pm}$. Logarithmic scales like $\mathrm{dB}$ diminish the apparent magnitude of the impacts. A $3 \mathrm{~dB}$ increase corresponds to a $29 \%$ reduction in the distance a vigilant animal can detect a predator and a $50 \%$ reduction in the area an acoustically-mediated predator can search for prey sounds (for signals in the frequency band of the noise).

Roads are another pervasive source of noise: $83 \%$ of the land area in the continental U.S. is within $1061 \mathrm{~m}$ of a road (Ritters and Wickham 2003). At this distance an average automobile - having a noise source level of $68 \mathrm{~dB}(\mathrm{~A})$ measured at $15 \mathrm{~m}$ - will project a noise level of $19.9 \mathrm{~dB}(\mathrm{~A})$. This exceeds the median natural levels of low frequency sound in most environments. Trucks and motorcycles will project substantially more noise: up to $40 \mathrm{~dB}(\mathrm{~A})$ at $1 \mathrm{~km}$, equivalent to the noise from 100 closely spaced automobiles.

1 Decibel (dB): a logarithmic measure of acoustic intensity. $0 \mathrm{~dB}$ approximates the lowest threshold of healthy human hearing, corresponding to an intensity of $10^{-12} \mathrm{~W} / \mathrm{m}^{2}$. Example sound intensities: $-20 \mathrm{~dB}$, sound just audible to a bat, owl or fox; $10 \mathrm{~dB}$, leaves rustling, quiet respiration; $60 \mathrm{~dB}$, average human speaking voice; $80 \mathrm{~dB}$, motorcycle at 15 meters.

A-weighting: A method of summing sound energy across the frequency spectrum of sounds audible to humans. It is a broadband index of loudness in humans in units of $\mathrm{dB}(\mathrm{A})$ or $\mathrm{dBA}$. A-weighting also approximates the shapes of hearing threshold curves in birds (Lohr et al. 2003). 


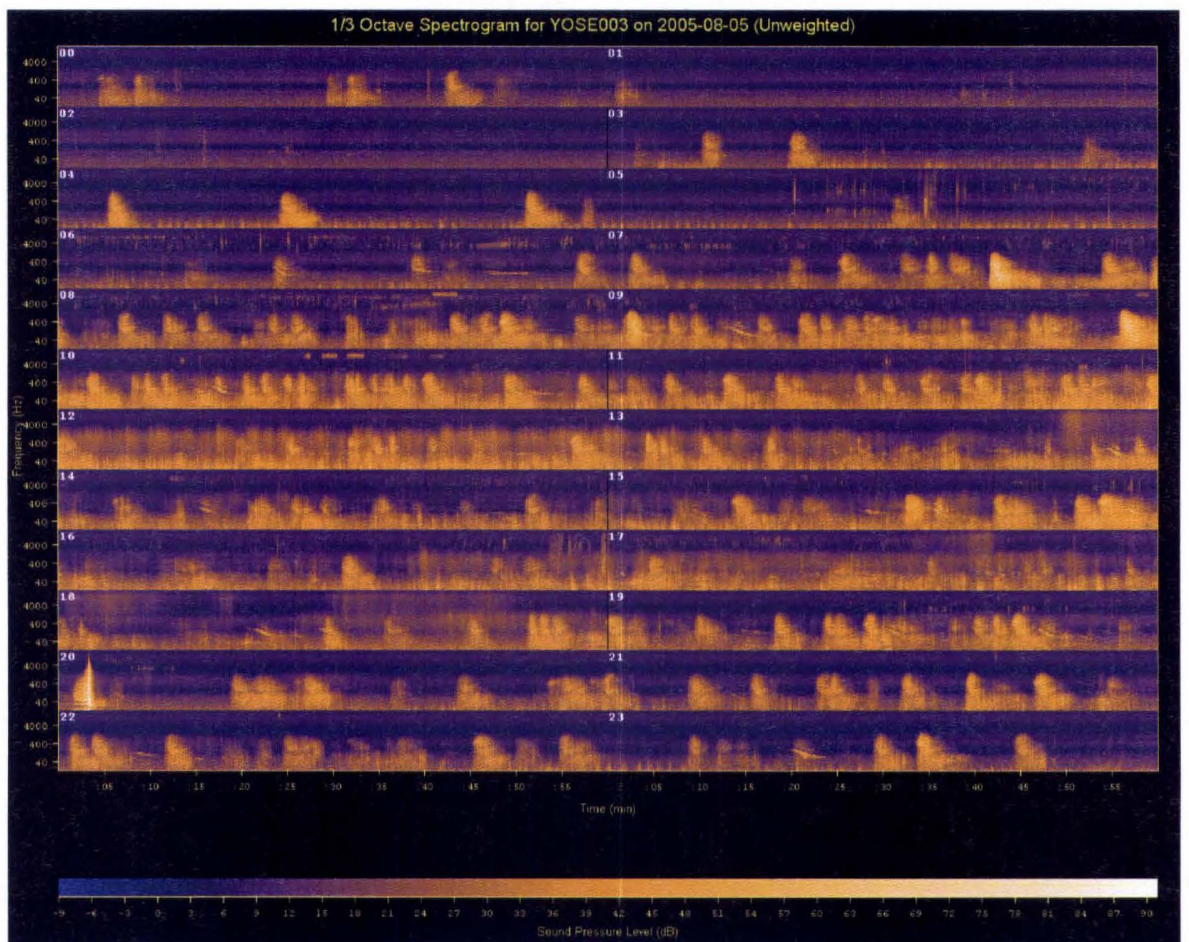

Figure 1. 24-hour spectrogram of Snow Flats backcountry site in Yosemite National Park, USA.

This spectrogram displays $1 / 3$ octave spectrum sound pressure levels for all hours of the day. Time is represented on the $\mathrm{x}$ axis with two hours on each row. Frequency is shown on the $\mathrm{y}$ axis as a logarithmic scale extending from $40 \mathrm{~Hz}$ to $4000 \mathrm{~Hz}$. The $\mathrm{z}$ axis (color) describes sound pressure levels in $\mathrm{dB}$ (unweighted). On this color scale, quiet levels appear dark blue while loud events appear orange or white. For reference, there are three airplane overflights in hour 03. Although this site is a backcountry site, analysis determined that anthropogenic noise was audible nearly 70 percent of the time during daylight hours. The morning bird chorus is faintly audible as a series of small dots just above $4000 \mathrm{~Hz}$, beginning at the end of hour 05 .

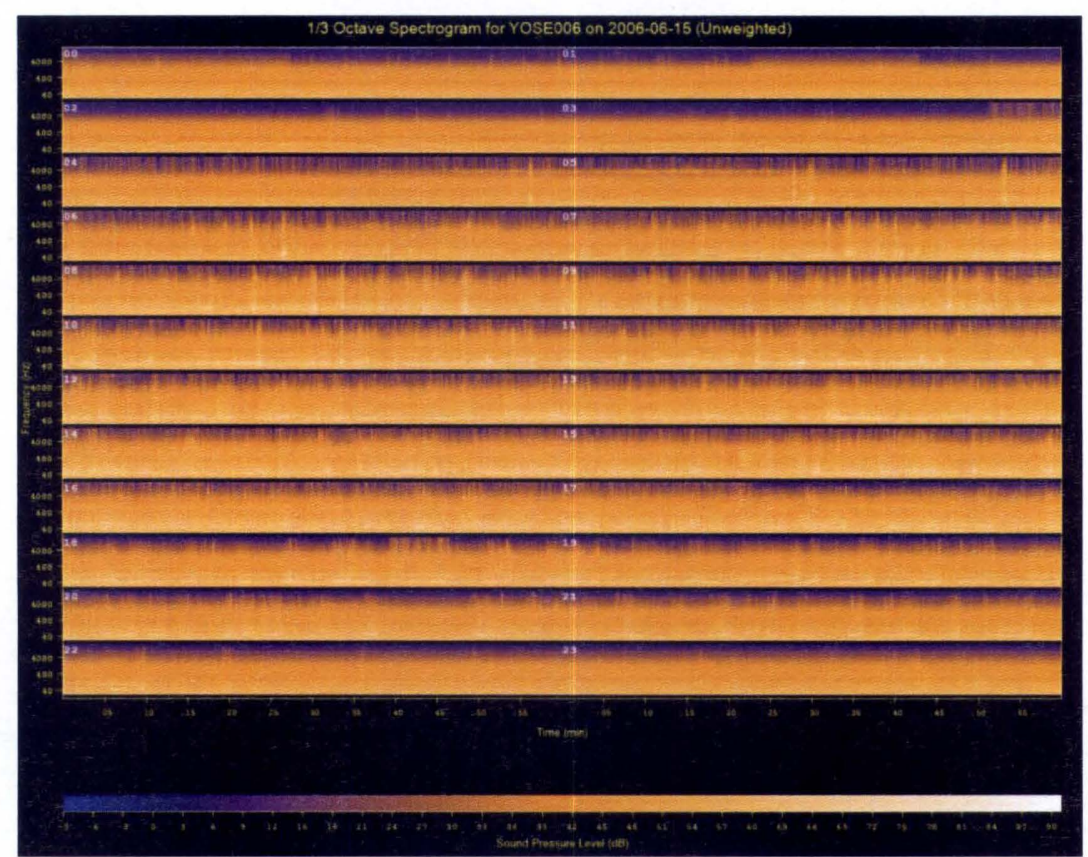

Figure 2. (a) 24-hour spectrogram of Yosemite Village site, USA.

See Figure 1 for spectrogram details. Yosemite Village lies along the main transportation corridor within Yosemite National Park, USA. Vehicle engine noise appears as lines colored bright yellow to white. Nighttime noise consists of heating and cooling equipment and transportation noise. 


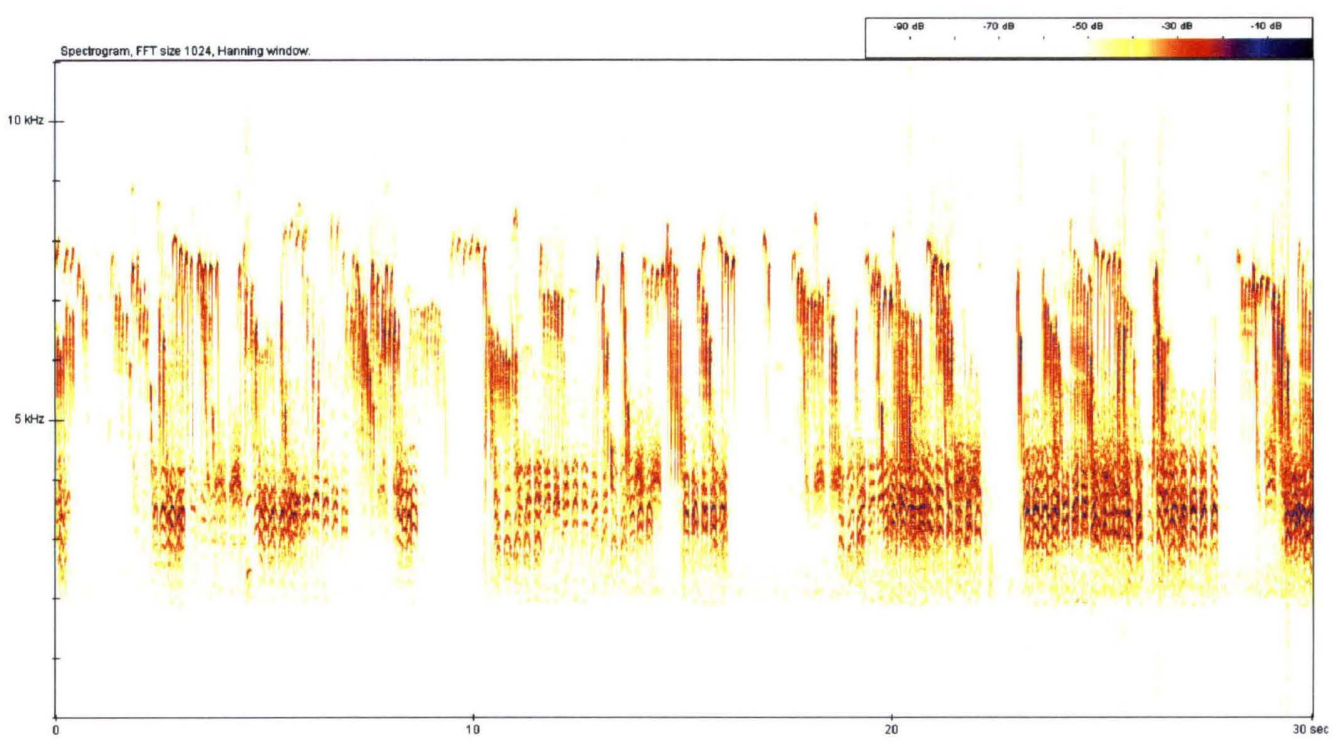

Figure 3. A spectrogram (frequency in Hertz $\times$ time in seconds) of a series of black-capped chickadee alarm calls used as a playback stimulus in hearing threshold experiments. The $\mathrm{z}$ axis (color) describes relative sound pressure levels in $\mathrm{dB}$.

Why is chronic exposure a significant threat to the integrity of organisms in terrestrial ecosystems? When noise elevates ambient sound levels, the capacity to detect acoustic signals of interest is degraded (Lohr et al. 2003). Masking is important because seemingly modest increases in ambient sound levels can have substantial effects. Numerous recent publications have documented changes in the characteristics of bird, primate, cetacean and squirrel vocalizations in response to increased noise exposure (Brumm and Slabbekoorn 2005; Slabbekoorn and Ripmeester 2007). These changes are attempts to reduce the masking of acoustical communication signals by anthropogenic noise.

We have been addressing the effects of manmade noise on animal communication systems by studying mixed songbird flocks along the Snake river corridor. The flocks are composed of such species as the black-capped chickadee (Poecile atricapill) and the red-breasted nuthatch (Sitta canadensis). Animal acoustic signals are constrained by the range over which they are above the threshold of the receiver and the background sound level. We are measuring the costs of acoustic masking by playing back biologically relevant signals to songbirds in varying levels of anthropogenic noise. Several classes of predation-related sounds (conspecific and heterospecific alarm calls and predator calls) are being played back to birds in $5 \mathrm{~dB}$ steps until the individual's behavior indicates a response to the stimulus. In this manner the hearing threshold for each bird is determined (see Figure 3 for an example playback stimulus). We use videographic threedimensional reconstruction techniques to quantify the received levels of both the auditory background and played back signal at the position of the bird. This approach is allowing the first quantitative assessment of auditory masking in the field. Laboratory masking studies on birds have used 'white' noise (an unnatural signal where energy is distributed equally across the frequency spectrum) whereas anthropogenic noise is heavily weighted to lower frequencies with most energy contained below $2000 \mathrm{~Hz}$. Signals are masked most effectively by energy contained within the same frequency range as the signal (Lohr et al. 2003) but other factors such as behavioral modifications by the receiver (head scanning, location or elevation change) and higher level cognitive processes are also likely to affect overall real-world masking levels (Brumm and Slabbekoorn 2005).

This work is taking place along the riparian corridors of the Snake and Gros Ventre rivers in Grand Teton National Park. Long-term sound monitoring by the Jackson Hole Airport (the only airport in a national park) near these research sites indicate a dramatic array of sound levels ranging from $20 \mathrm{~dB}(\mathrm{~A})$ to over 90 $\mathrm{dB}$ (A) (A DC-9 aircraft at one mile or a motorcycle at 25 feet; see http://maps.airportnetwork.com/JAC/). The goal of this ongoing study (expected completion date: 2011) is to quantify the hearing thresholds of songbirds in the wild and use the data to quantitatively estimate impacts under ever-increasing background sound levels from anthropogenic noise. 


\section{$\downarrow$ LITERATURE CITED}

Brumm H., H. Slabbekoorn. 2005. Acoustic communication in noise. Advances in the Study of Behavior 35:151-209

Lohr, B., et al. 2003. Detection and discrimination of natural calls in masking noise by birds: estimation of the active space of a signal. Anim. Behav. 65:763-777

Nowacek D.P., L.H. Thorne, D.W. Johnston and P.L. Tyack. 2007. Responses of cetaceans to anthropogenic noise. Mammal Review 37(2):81-115.
Ritters, K.H. and J.D. Wickham. 2003. How far to the nearest road? Front. Ecol. Environ. 1:125-129

Slabbekoorn H. and A.P. Ripmeester. 2007. Birdsong and anthropogenic noise: implications and applications for conservation. Molecular Ecology 17:72-83

Vitousek P.M., H.A. Mooney, J. Lubchenco and J.M. Melillo. 1997. Human domination of earth's ecosystems. Science 277:494-499 